\title{
Effect of Brazil's conditional cash transfer programme on tuberculosis incidence
}

\author{
J. S. Nery, ${ }^{*}$ L. C. Rodrigues, ${ }^{\dagger}$ D. Rasella, ${ }^{*}$ R. Aquino, ${ }^{*}$ D. Barreira, ${ }^{\ddagger}$ A. W. Torrens, ${ }^{\ddagger}$ D. Boccia, ${ }^{\dagger}$ \\ G. O. Penna,§ M. L. F. Penna, ๆ M. L. Barreto,* S. M. Pereira* \\ *Institute of Collective Health, Federal University of Bahia, Salvador, Bahia, Brazil; ${ }^{\dagger}$ Faculty of Epidemiology and \\ Population Health, London School of Hygiene \& Tropical Medicine, London, UK; ${ }^{\ddagger}$ National Program of Tuberculosis \\ Control, Brazilian Health Ministry, Brasília, Distrito Federal, §Tropical Medicine Center, University of Brasília, \\ Brasília, Distrito Federal, "Health Sciences Center, Institute of Community Health, Fluminense Federal University, \\ Niterói, Rio de Janeiro, Brazil
}

S U M M AR Y

OBJECTIVE: To evaluate the impact of the Brazilian cash transfer programme (Bolsa Família Programme, $\mathrm{BFP}$ ) on tuberculosis (TB) incidence in Brazil from 2004 to 2012.

DESIGN: We studied tuberculosis surveillance data using a combination of an ecological multiple-group and time-trend design covering 2458 Brazilian municipalities. The main independent variable was BFP coverage and the outcome was the TB incidence rate. All study variables were obtained from national databases. We used fixed-effects negative binomial models for panel data adjusted for selected covariates and a variable representing time.
RESULTS: After controlling for covariates, TB incidence rates were significantly reduced in municipalities with high BFP coverage compared with those with low and intermediate coverage (in a model with a time variable incidence rate ratio $=0.96,95 \% \mathrm{CI} 0.93-0.99$ ).

CONCLUSION: This was the first evidence of a statistically significant association between the increase in cash transfer programme coverage and a reduction in TB incidence rate. Our findings provide support for social protection interventions for tackling TB worldwide. Key words: TB; Bolsa Família Programme; Brazil
TUBERCULOSIS (TB) is a poverty-related disease. According to the World Health Organization, Brazil ranks sixteenth in the absolute number of cases and twenty-second in incidence rate worldwide. ${ }^{1}$ Brazil has shown a decline in mortality and incidence rates over recent decades. TB incidence declined at a rate of $19.3 \%$ between 2005 and 2014, reaching 33.5 per 100000 population at the end of this period $(68000$ new TB cases). ${ }^{2}$

In addition to individual risk factors, TB determinants include demographic, social and economic factors such as social inequality, poor housing, low education levels, overcrowding, difficulties in accessing public services and food shortages. ${ }^{3-5}$ TB incidence has declined faster in countries in which economic growth is associated with advances in social conditions and health care. In industrialised countries, the association between indicators of socio-economic development and $\mathrm{TB}$ incidence is clear $^{3,6}$ and has been verified in different contexts. ${ }^{7-9}$

In Brazil, a recent government recommendation suggested that TB control activities should be coordinated with other public policies, such as interventions to reduce poverty. ${ }^{10}$ In 2004, Brazil introduced what would become the largest conditional cash transfer programme worldwide, the Bolsa Família Programme (BFP), which covered nearly 14 million families in 2014. ${ }^{11}$ BFP has two main objectives: to transfer income to poor families and to improve access to education and health care. ${ }^{12}$ In the study period, families classified as 'extremely poor' (monthly per capita income $\leqslant$ US\$35) and 'poor' (monthly per capita income US\$35-US\$70 and with children aged $\leqslant 17$ years or pregnant or lactating women) are eligible to receive cash transfer after registration in the CadÚnico database for social programmes. Benefits vary from US\$18 to US\$175 per month.

Families considered to be 'extremely poor' can receive the benefit to overcome extreme poverty. Families may move out of extreme poverty but still be eligible for BFP because they are considered 'poor' according to the average per capita income and family composition. ${ }^{13}$ Enrolled families must meet education and health conditions (also known as 'conditionalities'): up-to-date vaccination and growth

Correspondence to: Joilda Silva Nery, Institute of Collective Health, Federal University of Bahia, Rua Basílio da Gama s/n Canela, 40.110-040 Salvador, Bahia, Brazil. e-mail: joildanery@gmail.com

Article submitted 5 August 2016. Final version accepted 13 March 2017. 
monitoring for children aged $<7$ years, and attendance during antenatal and postnatal care for pregnant women. ${ }^{13}$

There are no rules for beneficiaries on how the money may be spent. Nevertheless, cash transfers can improve household consumption, reduce food shortage and increase health and nutritional status. ${ }^{14}$ Studies have shown that social protection interventions, such as cash transfer programmes, contribute to strengthening TB control by improving household living conditions and reducing exposure to biological risk factors such as malnutrition. ${ }^{15,16}$ This strategy leads to increased access to and diversification of food intake and health-seeking behaviour, thus reducing people's vulnerability to TB infection and disease. ${ }^{15,16}$

In Brazil, there is evidence to suggest that BFP has reduced extreme poverty and alleviated social and economic inequalities, ${ }^{17,18}$ improved nutritional status $^{19}$ and reduced childhood mortality ${ }^{20,21}$ and leprosy incidence 22 by increasing income and improving food security and other health benefits among the most deprived individuals. ${ }^{13}$ Although BFP is not specifically targeted at TB-affected families, the programme focuses on poor households, which are consequently at high risk of TB. ${ }^{16}$

The objective of the present study was to evaluate the impact of the BFP on the TB incidence rate in Brazil.

\section{STUDY POPULATION AND METHODS}

We conducted a mixed ecological study (ecological multiple-group and time-trend panel data) with municipality as the unit of analysis from 2004 to 2012. Of 5000 Brazilian municipalities with available data, 2458 were selected based on the quality of TB surveillance data and ability to treat cases in the municipality. Eight indicators of Brazilian TB surveillance and their respective cut-offs were selected. The mean proportion of indicators in each municipality during the first 8 years of the study (20042011) was used for selection. Municipalities that met the criteria of at least three of the indicators of quality of $\mathrm{TB}$ detection and at least two indicators of information quality were considered to have 'adequate' quality. $^{23}$

\section{Data and data sources}

The main independent variable was BFP coverage of the target population, which was obtained from the Ministry of Social Development database. BFP coverage was defined as the 'number of families included in the programme by the municipality divided by the number of eligible families (according to BFP criteria) in the municipality'. ${ }^{11}$ BFP coverage in the target population was divided into three categories: low $(<30 \%)$, intermediate $(30-69 \%)$ and high $(\geqslant 70 \%)$.

The outcome was the annual incidence TB rate, which was calculated as the number of new TB cases all forms notified (defined by the codes A15-A19 of the International Classification of Diseases, tenth edition) per 100000 population. Data on the number of new TB cases notified was collected from the Notifiable Diseases Information System (Sistema de Informação de Agravos de Notificação) of the Ministry of Health, Brasilia, Brazil. ${ }^{24}$ The population of the municipalities was obtained from the national demographic census databases (including intercensus estimates) at the Brazilian Institute of Geography and Statistics, Rio de Janeiro, RJ, Brazil (Instituto Brasileiro de Geografia e Estatística, IBGE). ${ }^{25}$

We selected a set of covariates known as potential TB determinants: ${ }^{4}$ illiteracy rate, percentage of poor people in the municipality (proportion of individuals with per capita household income $\leqslant$ US $\$ 35$ per month at that time), unemployment rate, urbanisation rate, mean number of residents per household and the Gini Index. These variables were extracted for each municipality from the 2000 and 2010 IBGE national demographic census databases, ${ }^{25}$ with linear interpolation for 2004-2009 and linear extrapolation for 2011-2012.

The yearly coverage of the Family Health Programme (FHP), the main primary health care strategy in Brazil, was calculated as the number of individuals with records in any of the FHP facilities of the municipality in that year divided by the population of the municipality. This variable was obtained from the Primary Care Information System of the Ministry of Health. ${ }^{24}$

\section{Statistical analyses}

We present a descriptive analysis of trends in mean BFP coverage, TB incidence rate and covariates in the selected municipalities. We estimated the impact of $\mathrm{BFP}$ on the TB incidence rate using multivariable negative binomial regression models for panel data with fixed-effects specification, both crude and adjusted, for relevant covariates. Negative binomial regression models were used, as the outcome of study was a rate ( $\mathrm{TB}$ incidence rate) and the distribution was overdispersed. ${ }^{26-28}$

We estimated the TB incidence rate ratio (IRR), both crude and adjusted, for covariates. We present two fitness results: one including a variable for calendar year to take into account secular trends independent of BFP and another that did not include a time variable. The municipalities with low BFP coverage were used as the reference category.

All analyses were performed using Stata, version 13 (StataCorp, College Station, TX, USA). The Ethics Committee of the Institute Research for Collective Health of the Federal University of Bahia, Salvador, 
Table 1 Number of new cases and TB incidence rate in Brazil and in selected municipalities, 2004-2012 $(n=2458)$

\begin{tabular}{|c|c|c|c|c|c|}
\hline Year & $\begin{array}{c}\text { New TB cases: } \\
\text { study municipalities } \\
n \\
\text { (a) }\end{array}$ & $\begin{array}{c}\text { New TB cases } \\
\text { in Brazil } \\
n \\
\text { (b) }\end{array}$ & $\begin{array}{c}\text { Proportion of } \\
\text { total cases in Brazil } \\
\% \\
(a / b)\end{array}$ & $\begin{array}{c}\text { TB incidence rate: } \\
\text { study municipalities } \\
\text { /100000 }\end{array}$ & $\begin{array}{c}\text { Annual TB incidence } \\
\text { rate: Brazil } \\
\text { /100 } 000\end{array}$ \\
\hline 2004 & 72331 & 77694 & 93.1 & 46.1 & 43.4 \\
\hline 2005 & 71179 & 76468 & 93.1 & 44.5 & 41.5 \\
\hline 2006 & 68072 & 72213 & 94.3 & 42.0 & 38.7 \\
\hline 2007 & 67718 & 71825 & 94.3 & 42.3 & 37.9 \\
\hline 2008 & 69382 & 73536 & 94.4 & 42.3 & 38.8 \\
\hline 2009 & 69075 & 72962 & 94.7 & 41.6 & 38.1 \\
\hline 2010 & 67822 & 69433 & 97.7 & 40.9 & 36.4 \\
\hline 2011 & 69740 & 70731 & 98.6 & 41.8 & 36.8 \\
\hline 2012 & 67940 & 71230 & 95.4 & 38.8 & 36.7 \\
\hline
\end{tabular}

$\mathrm{TB}=$ tuberculosis.

BA, Brazil (protocol number 200.900) approved our study protocol.

\section{RESULTS}

More than $93 \%$ of all new TB cases diagnosed in Brazil were notified and lived in the 2458 municipalities included in this study (Table 1). Figure 1 shows the increase in BFP coverage among the target population, from $61 \%$ to $93 \%$, between 2004 and 2012. The TB incidence rate decreased from 46.1 to $38.8 / 100000 / y e a r$, corresponding to a decline of $15.8 \%$ in 9 years. The increase in BFP coverage and the decline in TB incidence were both more robust during the first 3 years of the study (2004-2006). During the study period, the reduction in $\mathrm{TB}$ incidence in the selected municipalities was approximately similar to that in Brazil as a whole.

Table 2 shows the trends in the main variables in the study municipalities. From 2005 to 2012, most of the municipalities had $\geqslant 70 \%$ BFP coverage in the target population. The mean municipality FHP coverage reached $69.4 \%$ in 2012 . There was remarkable progress in socio-economic indicators during the study period: reductions in the Gini Index, illiteracy rate, mean number of residents per household, percentage of poor people in the municipality and unemployment rate. The proportion of the population living in urban areas of the municipalities increased.

Table 3 shows the crude and adjusted association between TB incidence rate and BFP coverage over the period. When compared with municipalities with low and intermediate BFP coverage, municipalities with $\mathrm{BFP}$ coverage $\geqslant 70 \%$ had significant reductions in the TB incidence rate in the crude and adjusted models for socio-economic variables. In models without a variable representing overall time, the reduction in municipalities with high BFP coverage was $12 \%$ over this period (IRR $0.88,95 \%$ CI $0.85-0.91$ ). In the model adjusted for time and other covariates, the effect of BFP was 4\% (IRR 0.96, 95\% CI 0.93-0.99).
Variables significantly associated with TB incidence were the proportion of the illiterate population in the municipality, the proportion of the population living with per capita monthly household income $\leqslant$ US\$35 and, in the model including time, FHP coverage. The adjusted independent effect of time was significant, with all years having a statistically significantly lower TB incidence rate than the baseline year (2004). Unemployment rate, urbanisation rate, mean number of residents per household and the Gini Index were excluded from the model as they were not significantly associated with TB incidence rate and did not change the association between BFP coverage and TB incidence rate.

\section{DISCUSSION}

Our ecological-level analysis shows that municipalities with high BFP coverage had a statistically significant association with the reduction in $\mathrm{TB}$ incidence in a high TB burden country such as Brazil. TB incidence has decreased in recent decades in Brazil, ${ }^{2}$ and our results suggest that BFP may have contributed, at least in part, to this reduction, although the programme was not developed for TB control.

We did not investigate the mechanism by which cash transfers contributed to the reduction in TB incidence, but this reduction is consistent with our understanding of the role of social determinants on TB incidence based on historical trends. The occurrence of new TB cases has two components: new infections with Mycobacterium tuberculosis or progression from latent infection to disease. Infection with M. tuberculosis is related to crowding, housing conditions and organisation of urban spaces. It could be argued that the financial benefit of BFP (a maximum of US\$175 a month for a family with at least one child, teenager or pregnant woman) is likely to be too small to influence TB incidence.

Progression of TB disease and time elapsed since a person has become infected are determined by a range 


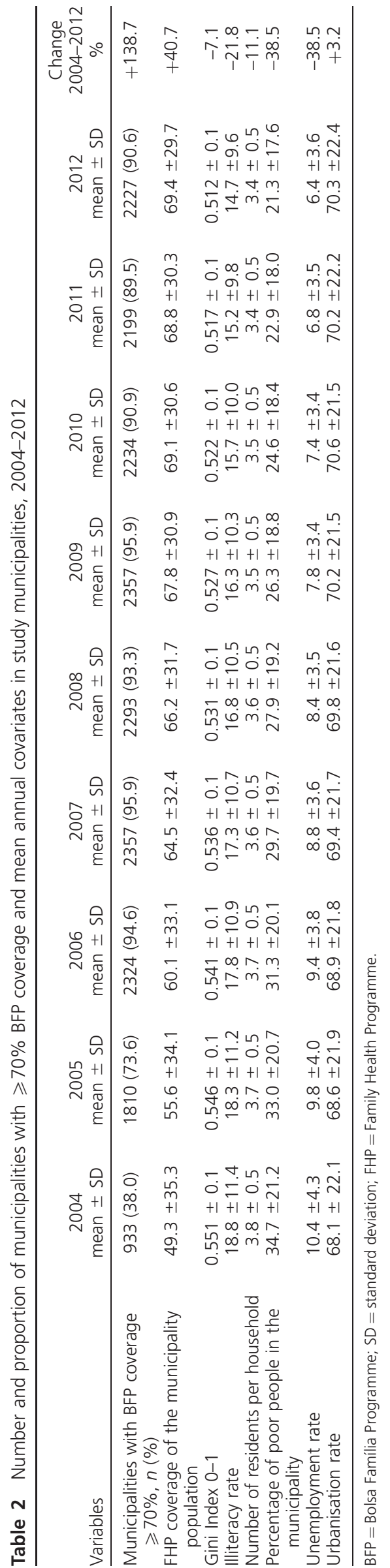

of factors, which BFP can address. Cash transfer itself may have a direct effect on the reduction in TB incidence, leading to improved living conditions and reducing potential risk factors for progression to TB disease. ${ }^{15,16}$ One hypothesis is that undernutrition and food shortage increase the risk of development of active TB. ${ }^{5,29}$ Cash-transfer interventions such as BFP are related to increasing food intake and variability in diet quality. ${ }^{30,31}$ In conclusion, although BFP may reduce people's vulnerability to progression to TB disease, probably through its financial benefits, it may have a smaller or no impact on TB transmission in highly endemic countries such as Brazil.

The effect of BFP on the reduction in the TB incidence rate in Brazil was consistent with the only other study on the impact of investments in social protection programmes on $\mathrm{TB}$, which was undertaken in 21 European countries over 18 years. ${ }^{32}$ The authors were reluctant to generalise their results to middle- and low-income countries, and suggested that social protection interventions might lead to greater benefits in poorer countries.

Should we have expected a higher reduction of TB incidence in our analysis? There are some reasons to suggest that the response might be 'no', and these are methodological, programmatic and biological. Methodological reasons include the fact that we were examining the effect at the municipality level. Programmatic reasons include characteristics of BFP that make it difficult to reach some populations at high risk of $\mathrm{TB}$ (e.g., the homeless), and other individuals at risk of TB, with lower income than is required for BFP enrolment. Biological mechanisms include the long incubation period of TB, which might lead to medium- rather than short-term effects, and other determinants, such as the prevalence of human immunodeficiency virus (HIV) infection and diabetes, smoking, drug use and alcohol consumption. ${ }^{3}$ Policies and preventive actions aimed at reducing the prevalence of these factors may have contributed to the additional reduction in $\mathrm{TB}$ incidence.

There is strong evidence of the effectiveness of BFP in reducing childhood mortality, ${ }^{21}$ especially by causes related to poverty. With regard to infectious diseases, these effects have been linked to diarrhoea and pneumonia. ${ }^{20}$ BFP was associated with a reduction of $11 \%$ in leprosy incidence, which shares some social determinants with TB. ${ }^{22}$ Another study, by Pettifor et al., reviewed other conditional cash transfer programmes on HIV prevention in other countries. ${ }^{33}$

\section{Limitations}

The present study had some methodological innovations but also limitations. We used panel data, a consolidated statistical methodology that allowed us to analyse a time series of 9 years for each 
Table 3 Association between the incidence rate ratio of TB and BFP coverage, Brazil, 2004-2012

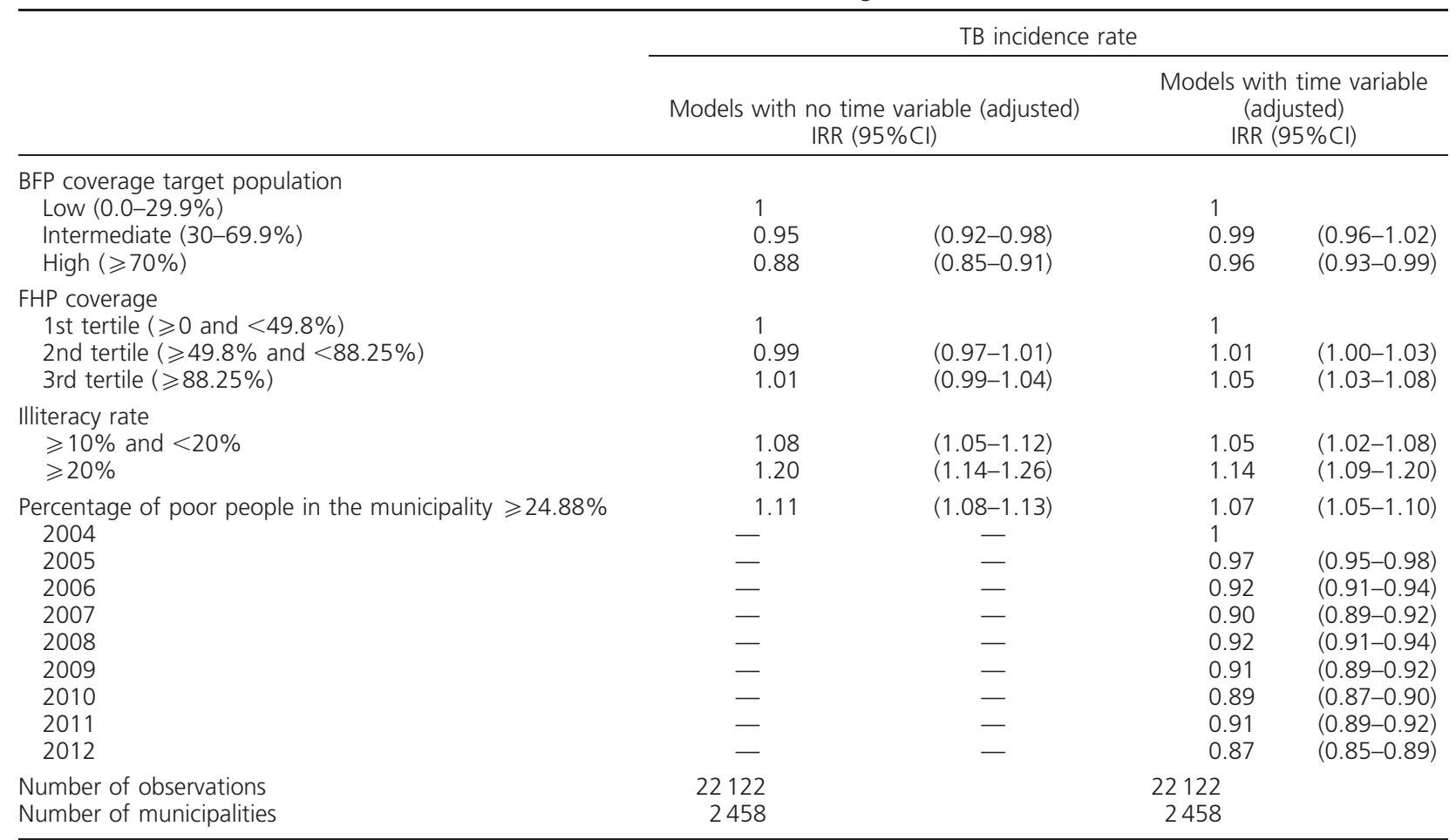

$\mathrm{IRR}=$ incidence rate ratio; $\mathrm{TB}=$ tuberculosis; $\mathrm{BFP}=$ Bolsa Família Programme; $\mathrm{Cl}=$ confidence interval; FHP = Family Health Programme

municipality in the database. Panel data analysis is a more sophisticated approach than using cross-sectional data, as it allowed us to define a time-series analysis for each municipality and compare trends in TB rates among them based on the category of BFP coverage. ${ }^{28}$ We used the municipality as our unit of analysis due to data availability and because there were variations in BFP coverage among municipalities, as BFP was implemented at the municipality level. ${ }^{13}$ Finally, our study investigated the effect of BFP coverage on the TB rate at municipality level. We did not use information at the individual level, and the findings should not be interpreted as the effect that an individual receiving BFP would have on his/ her risk of developing active TB.

We do not believe that under-reporting was a problem in our study. Brazil has a single surveillance information system and TB has been a nationally notifiable disease for many years: Municipal Health Secretaries are required to notify each newly diagnosed TB case to the Ministry of Health. However, as some Brazilian municipalities have deficiencies in TB surveillance, including under-reporting or misclassified cases, ${ }^{23}$ we included only municipalities with

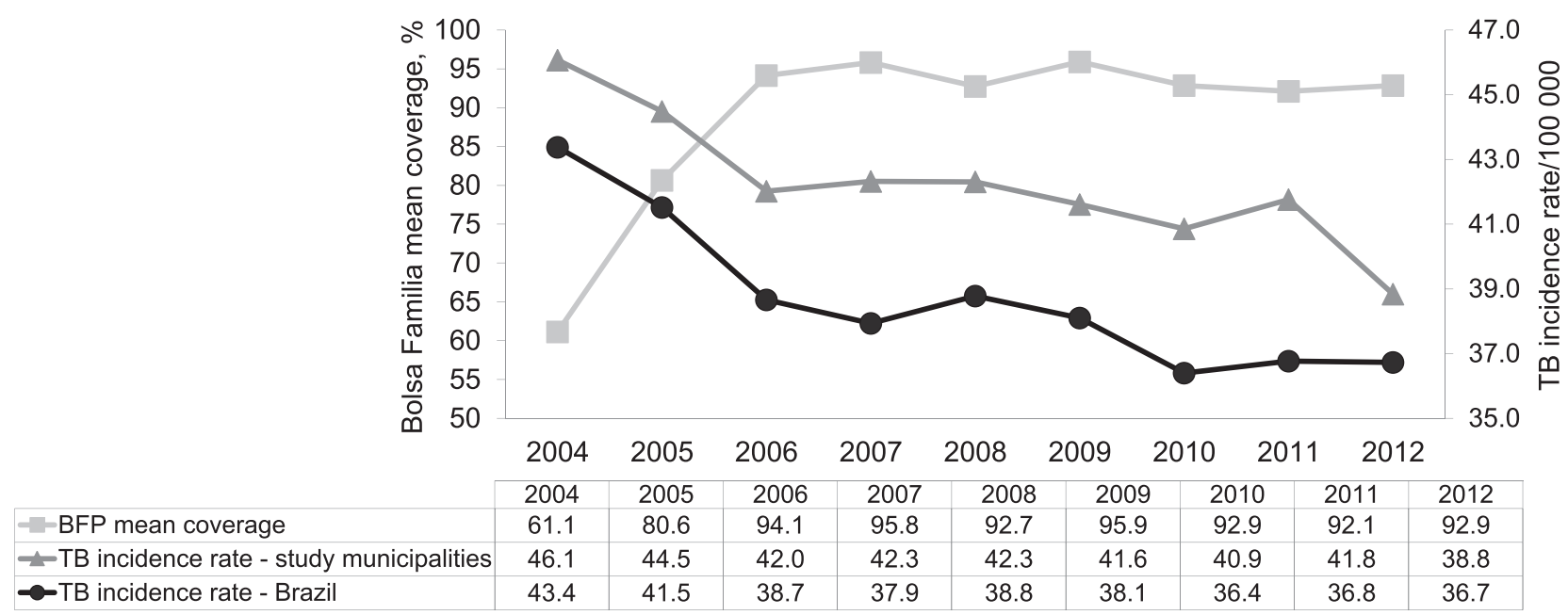

Figure Mean BFP coverage (\%) of target population and TB incidence rate (/100 000) in the study municipalities $(n=2458)$ and in Brazil as a whole, 2004-2012. TB $=$ tuberculosis; BFP $=$ Bolsa Família Programme. 
adequate quality TB surveillance data in our analysis. This was done to improve the internal validity of our study. A similar analysis involving all Brazilian municipalities with regard to TB surveillance quality produced similar effect estimates. We were able to include estimates for most of the known TB determinants. The annual values of sociodemographic variables were obtained from linear interpolation and extrapolation from a decennial census; it is unlikely that small errors in these estimates would distort the results.

\section{CONCLUSIONS}

To the best of our knowledge, this is the first study to investigate the potential contribution of cash transfer programmes in reducing TB by tackling important social determinants of the disease. Our analysis contributes to evidence supporting the role of future social protection interventions in the fight against TB. ${ }^{1}$

We have demonstrated that a cash transfer programme, even if it does not specifically target $\mathrm{TB}$, might contribute to a reduction in the $\mathrm{TB}$ incidence rate in a large middle-income country. These results are encouraging and will stimulate other scientific efforts to elucidate mechanisms for the impact of cash transfer interventions on the burden of $\mathrm{TB}$ and other poverty-related infectious diseases. Future research should include individual-based observational studies and prospective impact evaluations to assess the effectiveness and cost-effectiveness of these interventions, and how they can realistically become part of the programmatic response to TB control worldwide. BFP has been established as an inclusive public policy which has a positive impact on poverty reduction, particularly with respect to poverty-related diseases.

\section{Acknowledgements}

Financial support for the study was provided by the Secretary of Health Surveillance, Brazilian Ministry of Health, Brasilia, Brazil. JSN was provided with a scholarship by the National Council for Scientific and Technological Development (Conselho Nacional de Desenvolvimento Científico e Tecnológico, CNPq, Brasilia, DF, Brazil).

The funders had no role in study design, data collection/analysis, decision to publish, or preparation of the manuscript.

Conflicts of interest: none declared.

\section{References}

1 World Health Organization. Global tuberculosis report, 2014. WHO/HTM/TB/2014.08. Geneva, Switzerland: WHO, 2014. http://apps.who.int/iris/bitstream/10665/137094/1/ 9789241564809_eng.pdf?ua=1 Accessed April 2017.

2 Ministry of Health, Brazil. Tuberculosis epidemiological report, 2015. Brasilia, DF, Brazil: Moh, 2015. http://portalsaude.saude. gov.br/images/pdf/2015/marco/27/2015-007---BETuberculose-- para-substitui----o-no-site.pdf Accessed April 2017.
3 Lönnroth K, Jaramillo E, Williams B G, Dye C, Raviglione M. Drivers of tuberculosis epidemics: The role of risk factors and social determinants. Soc Sci Med 2009; 68: 2240-2246.

4 San Pedro A, Oliveira R M. Tuberculosis and socioeconomic indicators: systematic review of the literature. Rev Panam Salud Publica 2013; 33: 294-301.

5 Odone A, Houben R M, White R G, Lönnroth K. The effect of diabetes and undernutrition trends on reaching 2035 global tuberculosis targets. Lancet Diabetes Endocrinol 2014; 2: 754764.

6 Dye C, Lönnroth K, Jaramillo E, Williams B G, Raviglione M. Trends in tuberculosis incidence and their determinants in 134 countries. Bull World Health Organ 2009; 87: 683-691.

7 McKeown T, Record R G. Reasons for the decline of mortality in England and Wales during the nineteenth century. Popul Stud 1962; 16: 94-122.

8 Shilova M V, Dye C. The resurgence of tuberculosis in Russia. Phil Trans R Soc Lond B 2001; 356: 1069-1075.

9 Odone A, Signorelli C, Rodrigues L C. Tuberculosis and the economic crisis: an old threat for the new European agenda. Scand J Public Health 2014; 42: 834-835.

10 National Health Council, Brazil. Resolution n 444 of 6 July 2011. The resolution about the confrontation of tuberculosis in Brazil. Brasilia, DF, Brazil: NHC, 2011. http://conselho.saude. gov.br/resolucoes/reso_11.htm Accessed April 2017.

11 Ministry of Social Development and Fight against Hunger, Brazil. Social Information Matrix. Brasilia, DF, Brazil: Ministry of Social Development and Fight against Hunger, 2007. http:// aplicacoes.mds.gov.br/sagi/mi2007/tabelas/mi_social.php Accessed April 2017.

12 Brazil. Lei $\mathrm{n}^{\circ}$ 10.836, de 9 de janeiro de 2004. Cria o Programmea Bolsa Família e dá outras providências. Brasilia, DF, Brazil: Government of Brazil, 2004. http://www.planalto. gov.br/ccivil_03/_Ato2004-2006/2004/Lei/L10.836.htm Accessed April 2017.

13 Neri M C, Campello T. Bolsa Família Programme: a decade of inclusion and citizenship. Brasilia, DF, Brazil: Instituto de Pesquisa Econômica Aplicada, 2013.

14 Gaarder M M, Glassman A, Todd J E. Conditional cash transfers and health: unpacking the causal chain. J Dev Effect 2010; 2: 6-50.

15 Hargreaves J R, Boccia D, Evans C A, Adato M, Petticrew M, Porter J D. The social determinants of tuberculosis: from evidence to action. Am J Public Health 2011; 101: 654-662.

16 Boccia D, Hargreaves J, Lönnroth K, et al. Cash transfer and microfinance interventions for tuberculosis control: review of the impact evidence and policy implications. Int J Tuberc Lung Dis $2011 ; 15$ : 37-49.

17 Soares S, Osório R G, Silveira F G. The impact of the benefit of Bolsa Família Programme on inequality and poverty. Brasilia, DF, Brazil: Instituto de Pesquisa Econômica Aplicada, 2010.

18 Hoffmann R. A recente queda da desigualdade de renda no Brasil: análise dos dados da PNAD, dos censos demográficos e das contas nacionais. Econômica 2008; 10: 7-39. [Portuguese]

19 Santos L M P, Paes-Sousa R, Soares M D, et al. Nutritional profile of children under five years of the Brazilian semi-arid. Evaluation of policies and programmes. Brasilia, DF, Brazil: Ministry of Social Development and Fight against Hunger, 2007: pp 347-382.

20 Rasella D, Aquino R, Santos C A, Paes-Sousa R, Barreto M L. Effect of a conditional cash transfer programme on childhood mortality: a nationwide analysis of Brazilian municipalities. Lancet 2013; 38: 57-64.

21 Guanais F C. The combined effects of the expansion of primary health care and conditional cash transfers on infant mortality in Brazil, 1998-2010. Am J Public Health 2013; 103: 2000-2006.

22 Nery J S, Pereira S M, Rasella D, et al. Effect of the Brazilian conditional cash transfer and primary health care programs on 
the new case detection rate of leprosy. PLoS Negl Trop Dis 2014; 8: e3357.

23 Braga J U. Tuberculosis surveillance and health information system in Brazil, 2001-2003. Rev Saúde Pública 2007; 41: 77 88.

24 Ministry of Health, Brazil. Department of Informatics of SUS. Brasilia, DF, Brazil: MoH. http://www.datasus.gov.br/datasus/ index.php Accessed November 2014.

25 Instituto Brasileiro de Geografia e Estatística. Brazilian Institute of Geography and Statistics. Rio de Janeiro, RJ, Brazil: IBGE, 2017. http://www.ibge.gov.br Accessed November 2014.

26 Hilbe J M. Negative binomial regression. Cambridge, UK: Cambridge University Press, 2011.

27 Khandker S R, Koolwal G B, Samad H A. Handbook on impact evaluation: quantitative methods and practices. Washington DC, USA: World Bank Publications, 2010.

28 Wooldridge J M. Introductory econometrics, a modern approach. $3^{\text {rd }}$ ed. Cincinnati, OH, USA: South-Western College Publishers, 2005.
29 Tekkel M, Rahu M, Loit H M, Baburin A. Risk factors for pulmonary tuberculosis in Estonia. Int J Tuberc Lung Dis 2002; 6: 887-894.

30 Hoddinott J S E, Washburn R. The impact of PROGRESA on consumption: a final report. Washington DC, USA: International Food Policy Research Institute, 2000.

31 Paes-Sousa R, Santos L M, Miazaki E S. Effects of a conditional cash transfer programme on child nutrition in Brazil. Bull World Health Organ 2011; 89: 496-503.

32 Reeves A, Basu S, McKee M, Stuckler D, Sandgren A, Semenza J. Social protection and tuberculosis control in 21 European countries, 1995-2012: a cross-national statistical modelling analysis. Lancet Infect Dis 2014; 14: 1105-1112.

33 Pettifor A, MacPhail C, Nguyen N, Rosenberg M. Can money prevent the spread of HIV? A review of cash payments for HIV prevention. AIDS Behav 2012; 16: 1729-1738. 
O В JE CTIF : Evaluer l'impact du programme brésilien de transfert d'argent (Bolsa Família Programme) sur l'incidence de la tuberculose (TB) au Brésil de 2004 à 2012.

SCHÉMA : Ceci a été une étude des données de la surveillance de la TB grâce à une combinaison d'un schéma écologique à groupes multiples et tendance dans le temps avec 2458 municipalités brésiliennes. La principale variable indépendante a été la couverture du Programme de la Bolsa Família et le résultat a été le taux d'incidence de la TB. Toutes les variables de l'étude ont été obtenues des bases de données nationales. Nous avons utilisé des modèles à effets fixes négatifs binomiaux pour les données du panel ajustées pour les covariables sélectionnées et une variable représentant le temps.
RÉSULTATS : Après contrôle des covariables, les taux d'incidence de la TB ont été significativement réduits dans les municipalités ayant une couverture élevée du Programme Bolsa Família comparées à celles dont la couverture par le Programme Bolsa Família était basse ou intermédiaire (dans le modèle avec variable dans le temps IRR 0,96 ; IC95\% 0,93-0,99).

CONCLUSION : Ceci a été la première preuve d'une association significative entre l'augmentation de la couverture du programme de transfert d'argent et de la réduction du taux d'incidence de la TB. Nos résultats contribuent à soutenir le rôle des interventions de protection sociale dans le combat contre la TB dans le monde.
O вJETIVo: Evaluar el impacto del programa de transferencia de efectivo (Programa Bolsa Familia) sobre la incidencia de tuberculosis (TB) del 2004 al 2012 en el Brasil.

MÉTODO: Fue este un estudio de los datos de vigilancia de la TB mediante un método mixto de estudio ecológico con grupos multidimensionales y de tendencias temporales en 2458 municipios del Brasil. La principal variable independiente fue la cobertura del Programa Bolsa Familia y el criterio de valoración fue la tasa de incidencia de TB. Toda la información sobre las variables del estudio se obtuvo de las bases de datos nacionales. Se utilizaron modelos de regresión binomial negativa con especificación de efectos fijos para los datos de panel, que se ajustaron con respecto a las covariables pertinentes y una variable correspondiente al tiempo.
RESULTADOS: Tras ajustar con respecto a las covariables, las tasas de incidencia de TB se redujeron de manera significativa en los municipios que contaban con una alta cobertura del Programa Bolsa Familia, en comparación con los que tenían una cobertura baja o intermedia (en el modelo con variable temporal, el cociente de tasas de incidencia fue 0,96 ; IC $95 \%$ de 0,93 a 0,99 ).

CONCLUSIÓn: Esta es la primera prueba de una correlación significativa entre la ampliación de cobertura del programa de transferencia de efectivo y la disminución de la tasa de incidencia de TB. Estos resultados aportan datos fidedignos que respaldan la importancia de las intervenciones de protección social en la lucha mundial contra la TB. 